\title{
Servikal dejeneratif hastalıklarda spinal enstrümantasyon
}

\author{
Spinal instrumentation in cervical degenerative diseases
}

\author{
İsmail Oltulu, Mehmet Aydoğan \\ Fulya Ortopedi ve Omurga Merkezi, İstanbul
}

\begin{abstract}
Servikal füzyonla ilişkili ilk bildiriler Cloward ve SmithRobinson tarafından yayımlanmıştır ve büyük bir kısmı nonunion'la sonuçlanan enstrümantasyonsuz olgulardır. ${ }^{[1,2]}$ Servikal anterior plak/vida tespiti ilk olarak Bohler tarafindan 1967'de tanımlanmıştır. ${ }^{[3]}$ Anterior servikal enstrümantasyon ilk olarak servikal travmalarda kullanılmıştır. Bu enstrümantasyonların belirgin yararından dolayı; özellikle multi-seviye dekompresyonlarda, allogreft kullanımında ve sigara içen servikal dejeneratif hastalarda kullanımı zamanla artmıştır. Statik ve dinamik sistemleri içeren birçok anterior plak sistemi mevcuttur; son zamanlarda, yük taşıyan anterior sistemler de araştırılmıştır. ${ }^{[4]}$ Posterior omurga füzyon sonuçları, başlangıçta dejeneratif olmayan olgular için bildirilmiştir. Illk olarak 1891 yılında Hadra, Pott hastalığında telleme yöntemini bildirmiştir. ${ }^{[5]}$ Posterior servikal plak tespiti, nispeten günümüzde kullanılmaya başlayan bir tekniktir. Illk olarak Roy-Camille ve Saillant tarafından 1970'de kullanılmaya başlamış ve 1988'de Cooper ve Cohen tarafindan yaygınlaştırılmıştır. ${ }^{[6,7]}$ Bu bölümde, servikal dejeneratif disk hastalıklarında kullanılan enstrümantasyon tekniklerinden bahsedilecektir.
\end{abstract}

Anahtar sözcülkler: servikal disk hastalığı; servikal enstrümantasyon tekniği; anterior; posterior
The first papers on cervical fusion are published by Cloward and Smith-Robinson and most of them were cases that resulted with non-union. Cervical anterior plate/screw fixation is first described by Bohler in 1967. Anterior cervical instrumentation is originally used in trauma cases. Due to the apparent benefit of these instruments their utilization has increased in time; especially in multi-level decompression, allograft use, and for cervical degenerative patients who smoke. There are many types of static and dynamic plate system available. Recently, load-carrying anterior systems have also been investigated. Posterior spine fusion results were initially reported for non-degenerative cases. First, in 1891, Hadra reported the wiring method in Pott's disease. Posterior cervical plaque fixation is relatively a recent technique. It was first used by Roy-Camille and Saillant in 1970 and popularized by Cooper and Cohen in 1988. In this section, instrumentation techniques used in cervical degenerative disc diseases will be mentioned.

Key words: cervical disc diseases; cervical instrumentation technique; anterior; posterior

instabiliteye neden olur. $\mathrm{C} 1$ ve $\mathrm{C} 2$, alt servikal bölgedeki omurlardan farklı anatomik özelliklere sahiptir. Bu bölgenin anatomik farklılığı ve vertebral arterin bu bölgede farklı bir seyir izlemesinden dolayı, C1-C2 tespiti oldukça güçtür. C1-C2 tespiti; telleme teknikleri, transartiküler vidalama ve rod ile vida tespitini içerir. C1 lateral mass vidası ve $C 2$ pedikül veya pars interartikülarisin modern vidalama yöntemi, Harms ve Mercher tarafından 2001 yılında tanımlanmıştır. ${ }^{[8]}$

C1-C2 tespiti, sıklıkla travmatik durumlarda (odontoid kırığı, C1-C2 instabil kırıkları), inflamatuvar hastalıklara bağlı instabiliteler (romatoid artrit vb.) ve konjenital veya gelişimsel durumlarda (os odontoideum, Down sendromu vb.) uygulanmaktadır. C1 ya da

Birçok dejeneratif, travmatik ve inflamatuvar durum, atlanto-aksiyel bölgede cerrahi stabilizasyon gerektiren

- Illetişim adresi: Op. Dr. İsmail Oltulu, Dikilitaş Mah. Ayazmadere Cad. Yeşilçimen Sok. No: 9/3 Kat: 3, Fulya, Beşiktaş, İstanbul Tel: 0212 - 2276338 e-posta: ioltulu@hotmail.com

- Geliș tarihi: 5 Nisan $2017 \quad$ Kabul tarihi: 5 Nisan 2017 


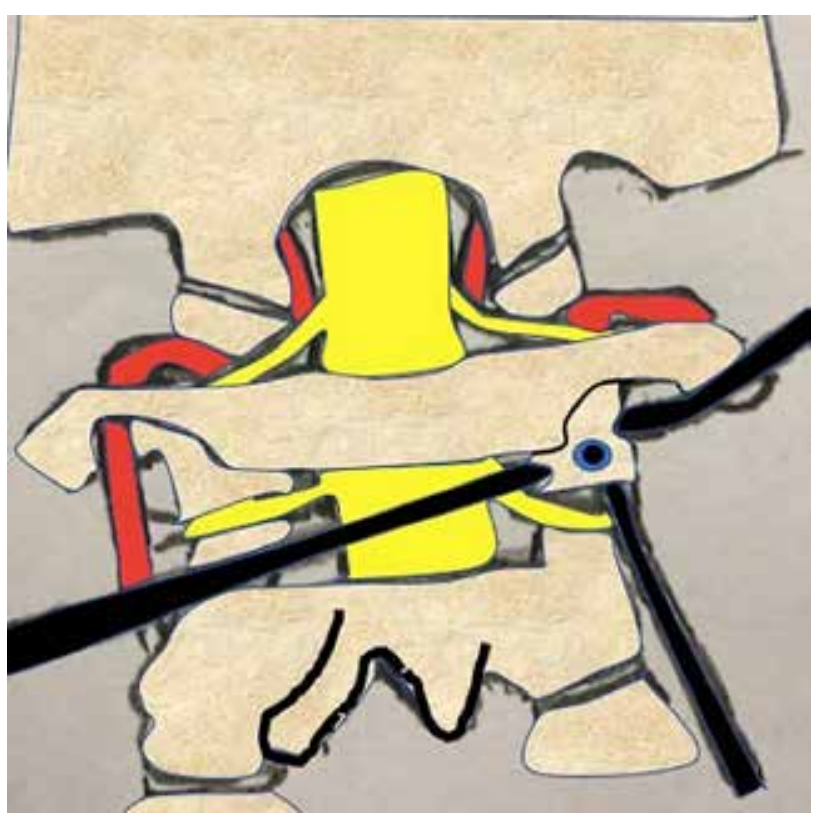

Şekil 1. $C 1$ vidası giriş noktası.

C2 vidası yerleştirilmesi düşünülüyorsa, cerrahi öncesi dönemde mutlaka vertebral arter anomalileri bakımından anjiyografi yapılmalıdır.

\section{CERRAHI TEKNIK}

\section{C1 Vida Tespiti}

C2'nin interartikülarisinin mediyal sınırını tespit etmek, C1 lateral mass vidasının giriş noktasının tespitine yardımcı olur. C1 lateral massının mediyali, bu noktanın hemen kraniyalindedir. Penfield ekartörle, C2 siniri hafifçe kaudale doğru ekarte edilir. C2 sinir kökünün etrafındaki venöz pleksus, kolaylıkla kanayabilir ve giriş noktasını kapatabilir. Giriş noktası, lateral mass'ın orta noktası belirlendikten sonra 2-2,5 $\mathrm{mm}$ drill ile işaretlenir (Şekil 1). Sıklıkla, aksiyel planda 5-10 $0^{\circ}$ mediyalizasyon ve hafif kraniyale yatarak, $\mathrm{C}^{\prime}$ 'in anterior tüberkülünün alt bölümü hedeflenir. Floroskopi ile trajeksiyon doğrulandıktan sonra tapp'leme yapılır. Parsiyel yivli 3,5-4 mm vida yerleştirilir. İnternal karotid arterin pozisyonuna göre, hem unikortikal hem de bikortikal vida yerleştirilebilir. ${ }^{[9,10]}$

\section{C2 Translaminar Vida Tespiti}

ilk olarak 2004 yılında, Wright tarafından tanımlanmıştır. Bu teknikle, anormal seyirli vertebral arter patolojilerinde arterin yaralanma riski ortadan kalkmaktadır. Yüksek hızlı burr ile spinöz proçes ve laminanın birleşim yeri işaretlenir; daha sonra vida her bir tarafta lamina boyunca yerleştirilir. Cerrahi öncesi bilgisayalı tomografi (BT) vida boyunu ve kalınlığını belirlemede yardımcı olacaktır. ${ }^{[11]}$

\section{C2 Pars Vidası}

Genel olarak, C2 pars ve pedikülünü tanımlamada bir karışıklık mevcuttur. C2'i parsı, C2'nin superior ve inferior artiküler faseti birleştiren dar kısmı olarak tanımlanmaktadır. ${ }^{[9]} \mathrm{C} 2$ pars vidasının giriş yeri, parsın mediyalinin yaklaşık $3 \mathrm{~mm}$ laterali ve $3 \mathrm{~mm}$ proksimalindedir. Pedikül vidasının giriş yerine göre daha kaudal ve daha mediyaldedir. Yüksekten dönen vertebral arter olgularında dikkatli olunmalıdır. Vida $10-15^{\circ}$ mediyale ve $35^{\circ}$ superiora yönlendirilmelidir. ${ }^{[9,12]}$

\section{C2 Pedikül Vidası}

Giriş noktası, C2 laminasının kraniyal sınırıdır. Yüksek hızı burr ile, giriş yeri belirgin hale getirilir. C2 pedikülünün superomediyalini tespit etmek için interlaminar aralığa bir Penfield ekartör yerleştirilir. Pedikül vidasının açısı, transvers planda orta hattan 15-20 olmalıdır. Daha sonra giriş yeri drill'enir ve tapp'leme yapılır. Topuz başlı bir probla pedikül kontrol edilir; 20-24 mm uzunluğunda vida kullanılabilir (Şekil 2). ${ }^{[13]}$

\section{OKSIPITOSERVIKAL STABILIZASYON}

Oksipitoservikal füzyon, genellikle kraniyoservikal instabilite veya deformite ile ilişkili durumlarda yapılmaktadır. Tipik endikasyonlar; travma, inflamatuvar hastalıklar, deformite, neoplazi ve çok nadiren enfeksiyon, dejeneratif hastalıklar ve konjenital displazilerdir. ${ }^{[14]}$ Tedavi edilmemiş instabilite veya kraniyoservikal ayrışma, progresif ağrı ve nörolojik fonksiyon bozukluğundan ölüme kadar uzanan tablolara neden olur.

\section{CERRAHI TEKNIK}

Kraniyoservikal bölgedeki instabilite, bu bölgede primer bir kemik stabilizatör olmamasına bağlı katastrofik sonuçlara neden olacak şekilde, nörovasküler yapıları risk altında bırakır. Şiddetli kraniyoservikal travmalarda, başlangıçta geçici tedavi için halo vest uygulanabilir. Traksiyon bu durumlarda uygulanmamalıdır. Definitif tedavisi, erken cerrahi stabilizasyondur. ${ }^{[15]}$ Inflamatuvar hastalıklara bağlı elektif olgularda, kademeli olarak, deformite redüksiyonu için birkaç gün halo ile birlikte iskelet traksiyonu uygulanabilir.

Suboksipital bölge, oksipital çıkıntının (occipital protuberance) $1 \mathrm{~cm}$ üzerini açacak şekilde hazırlanır. Elektrokoter ile orta hattan keskin disseksiyon yapılır. 


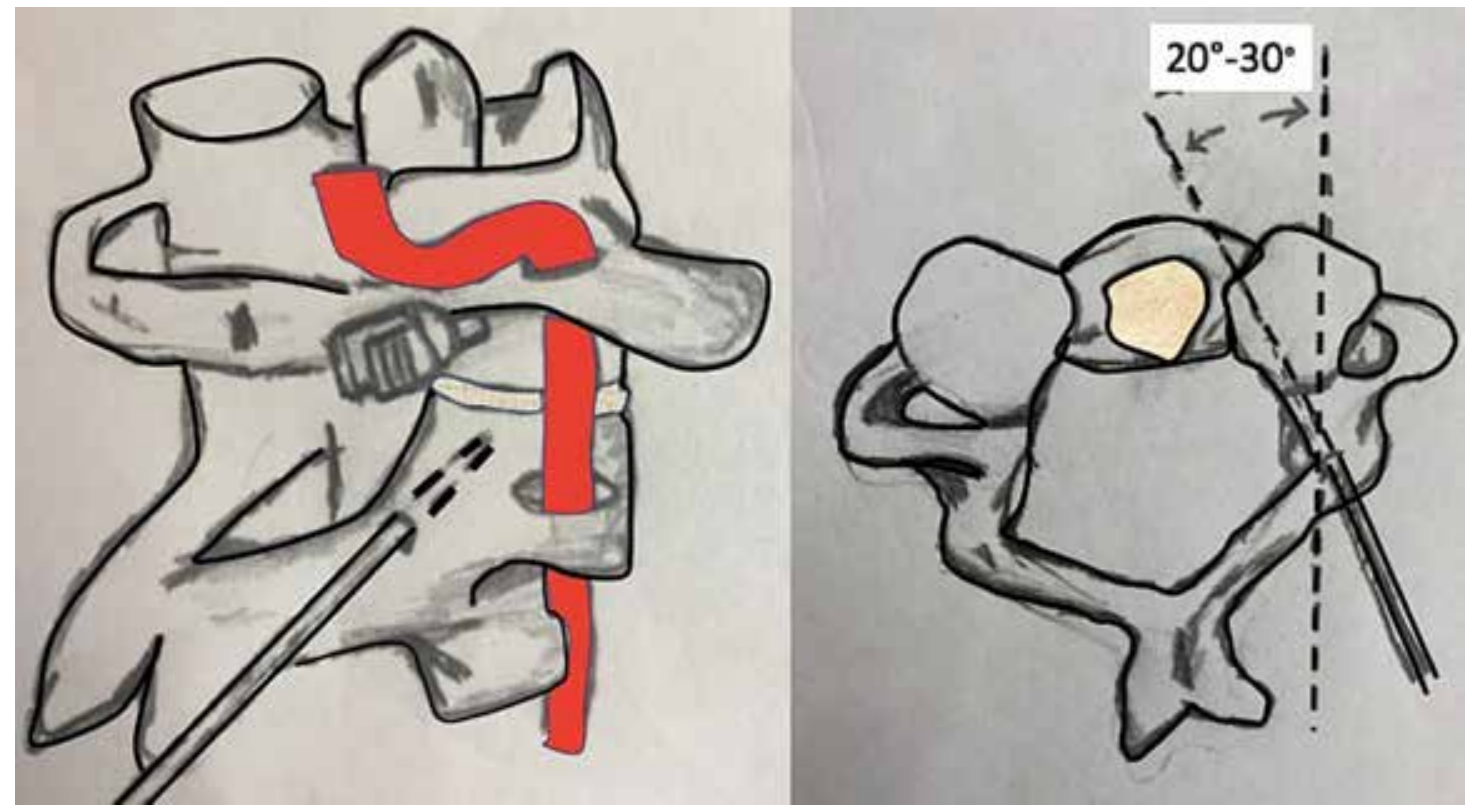

Şekil 2. C2 vidası giriş noktası.

C2 ve distalindeki interspinöz bağlantılar korunmalıdır. Fasyal planda yer alan oksipital sinir ve oksipital sinirin terminal dalının hasar görmemesine dikkat edilmelidir. Subperiostal disseksiyona C1, C2 ve C3, klinik endikasyonu varsa alt bölgeler boyunca devam edilir. C1 disseksiyonu yaparken vertebral arterin atlanto-oksipital membrana girmeden önceki bölümünün de zarar görmemesi için, disseksiyon orta hattan $1,5 \mathrm{~cm}$ laterale uzatılmamalıdır. C1-C2 posterior fasetin açılması, hem anatomik landmark'ların tanınmasına yardımcı olacak hem de atlanto-oksipital faset füzyonu kolaylaştıracaktır. Dekompresyon olguya bağlı olarak değişebilir. Tespitte, C1 lateral mass, C2 pars, pedikül veya translaminar vida ve gerekirse alt servikal bölge mass veya pedikül vidaları yerleştirilir. C1 lateral mass vidası yerleştirirken, ponticulus posticus (C1 posterior arkında, vertebral arter üzerindeki kemik köprü) noktasını akılda tutmak gerekmektedir. Longitudinal rod sistemleri ve orta hattı transvers geçen çeşitli oksipital plak tasarımları mevcuttur. Burada anahtar nokta, iyi bir füzyon için greft yerinin iyi hazırlanmasıdır. Tespit, $3,5^{\prime}$ lik üç ya da dört adet bikortikal tutunumlu kortikal vida ile sağlanır. Orta hat tespitleri sıklıkla laterale göre daha iyi bir tutunum sağlar. ${ }^{[16]}$ Drill'eme esnasında oluşan serebrospinal sıvı kaçağı, kesinlikle arzu edilmezken, vida yerleşimi sonrasında durmaktadır. Vida deliklerinin drill'enmesi, transvers sinus hasarına ve geç ölümcül komplikasyonlara neden olabilir.

\section{ALT SERVIKAL BÖLGE POSTERIOR STABILIZASYON}

Alt servikal bölgenin posterior yolla stabilizasyonu için birçok yöntem tanımlanmıştır. Bunlar; kemik grefti ile birlikte interspinöz telleme, interlaminer klempler, lateral mass vidaları, rod veya plakları ve pedikül vidalarını içerir. 1970'lerin sonlarında RoyCamille, lateral mass vidalarını biyomekanik testlerde kullanarak, posterior stabilizasyonun daha önceki yöntemlere oranla oldukça üstün olduğunu bildirmiştir. Transpediküler vida tespiti diğer yöntemlere oranla daha fazla tespit stabilitesi sağlar; ancak vertebral arter, spinal kord ve sinir kökü yaralanması gibi ciddi komplikasyonlara yol açma potansiyeli daha yüksektir. Bu nedenle, genel olarak yüksek riskli bir prosedür olarak kabul edilmektedir. ${ }^{[6,17-19]}$

Günümüzde, alt servikal bölgede hekimin deneyimine bağlı olarak pedikül vidası veya lateral mass vidası kullanılırken, $C 7$ vertebrada lateral mass'ın zayıf olması nedeniyle pedikül vidası tercih edilmektedir. Daha önceleri C6 mass vidası ile birlikte C7 pedikül vidasının konnekte edilmesi zorluklar içerirken, günümüzde rod vida sistemleri bu bağlantıyı daha kolay hale getirmiştir. Biz, bu bağlantıyı kolaylaştırmak için kendi geliştirdiğimiz çift rod sistemini kullanıyoruz.

Önerimiz alt servikal bölgede daha güvenilir bir yöntem olan mass vidasını tercih etmekten yana olsa 


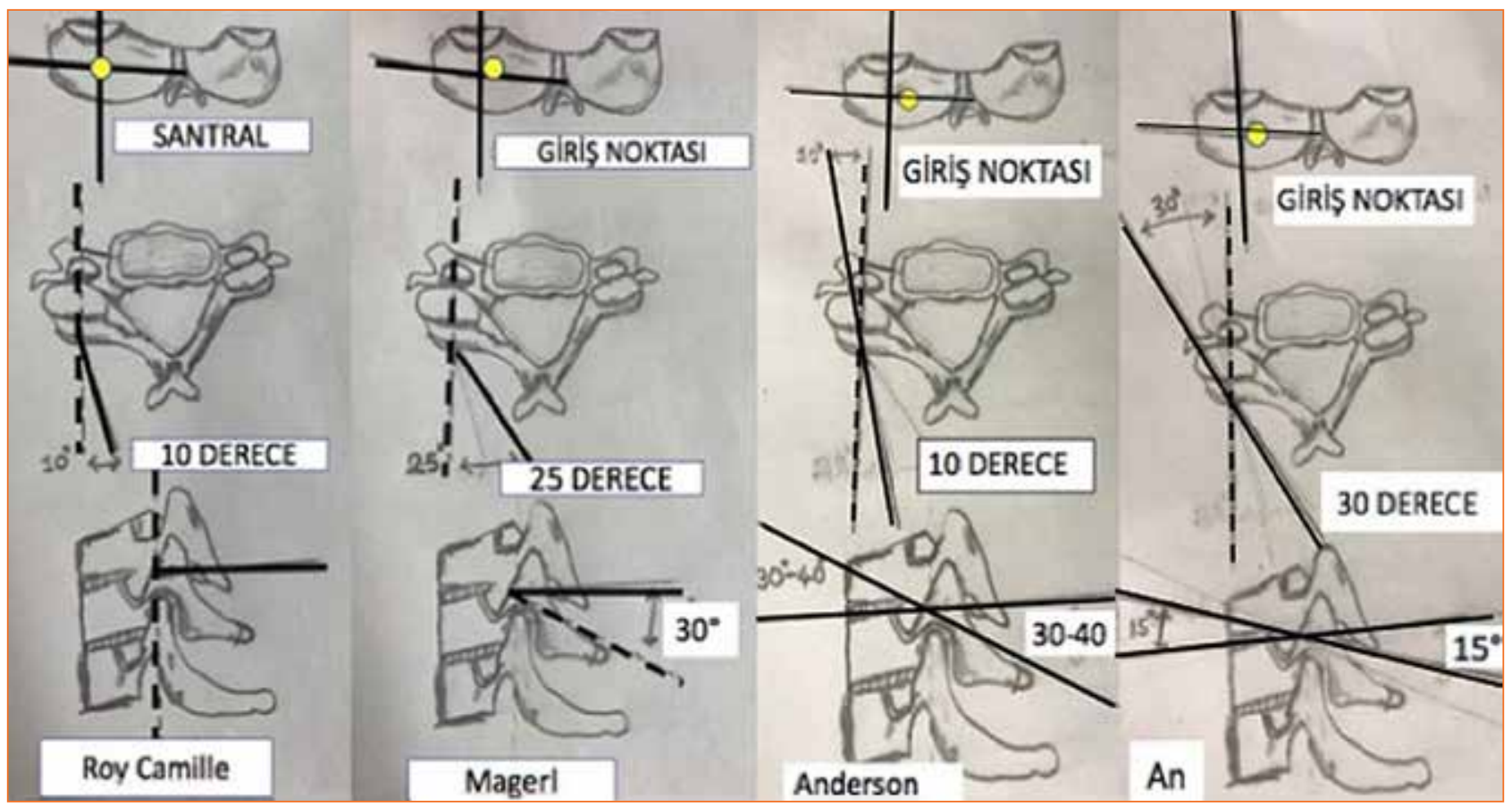

Şekil 3. Farklı tekniklerle mass vidası giriş noktaları.

da, özellikle lateral mass'ın veya laminanın geçirilmiş cerrahi sonrasında bozulmasına bağlı veya şiddetli osteoporoz varlığında mass vidalarının tutunum gücünün zayıf olacağını düşündüğümüz hastalarda tercihimiz, navigasyon eşliğinde pedikül vidalarının yerleştirilmesidir.

\section{ALT SERVIKAL FASET VIDASI}

Orta hat insizyonundan sonra, subperiostal disseksiyonla spinöz proçesler ve fasetler ortaya koyulur. Lateral mass'ın kuadrilaterali üst ve alt eklem ortaya konulup tanımlanır. Kuadrilateral alanın mediyali, lamina ve lateral mass birleşimindeki zayıf boşluktur. Lateral kenar elle palpe edilebilir. Dört kenar da belirlendikten sonra vida tespiti yapılır. Vertebral arter ve sinir kökü yaralanma riskini azaltmak için birçok teknik tanımlanmıştır. Roy-Camille'in tekniğinde giriş noktası kuadrantı mediyal, lateral ve superior, inferior olacak şekilde dört parçaya bölen iki çizginin orta noktasıdır. Bu teknikte vida, tranvers planda $10^{\circ}$ laterale açılanırken sagittal planda lateral mass'a dik olarak ilerletilmektedir. ${ }^{[6]}$ Magerl'in tekniğinde ise giriş noktası lateral massın orta noktasının $1 \mathrm{~mm}$ mediyali ve 1-2 $\mathrm{mm}$ kraniyalidir. Magerl'in tekniğinde, aksiyel planda $25^{\circ}$ laterale, sagittal planda faset eklemlere paralel olacak şekilde (yaklaşık $30^{\circ}$ ) kraniyale yönlenilmektedir. ${ }^{[20]}$ Roy-Camille'in tekniğinde bikortikal tutunumda vertebral arter risk altındayken, Magerl'in tekniğinde sinir kökü risk altındadır. Daha sonra yazarlar, anatomik çalışmalarda bikortikal tutunum için vidanın güvenli bölgesini superolateral aralık olarak belirlemişlerdir. Ancak burada, giriş noktası lateral mass'ın orta noktasının $1 \mathrm{~mm}$ mediyali ve gidiş yolu $15^{\circ}$ kraniyale ve $30^{\circ}$ laterale olacak şekilde belirlenmiştir (Şekil 3). ${ }^{[21]}$

Anderson'un tekniği, Magerl'in tekniğine benzemektedir. Sadece, giriş noktası daha az mediyal ve gidiş yolu daha az kraniyal ve lateral açılanma olacak şekildedir (Şekil 3). Bu teknikte, giriş noktası lateral mass'ın orta noktasının $1 \mathrm{~mm}$ mediyali ve vidanın gidiş açısı $10^{\circ}$ lateral ve $30-40^{\circ}$ kraniyal yöndedir. ${ }^{[22]}$ Biz kendi tekniğimizde, yüksek hızlı tur yardımı ile giriş noktalarını belirliyoruz. Giriş noktası, lateral mass'ı dört kadrana böldüğümüz zaman alt iç kadrandadır (Şekil 4). Tüm giriş noktalarını aynı zamanda belirliyoruz. Vidanın tam oturması için lamina mass bileşkesini turluyoruz (Şekil 5). Bu, hem laminektomiyi kolaylaştırıyor hem de füzyon için bir zemin oluşturuyor. Kirshner teli ile ilk girişi yaptıktan sonra, skopi kontrolü yapıp vidaları yerleştiriyoruz. Osteoporotik hastalarda bikortikal mass vidası yerleştiriyoruz (Şekil 6). 


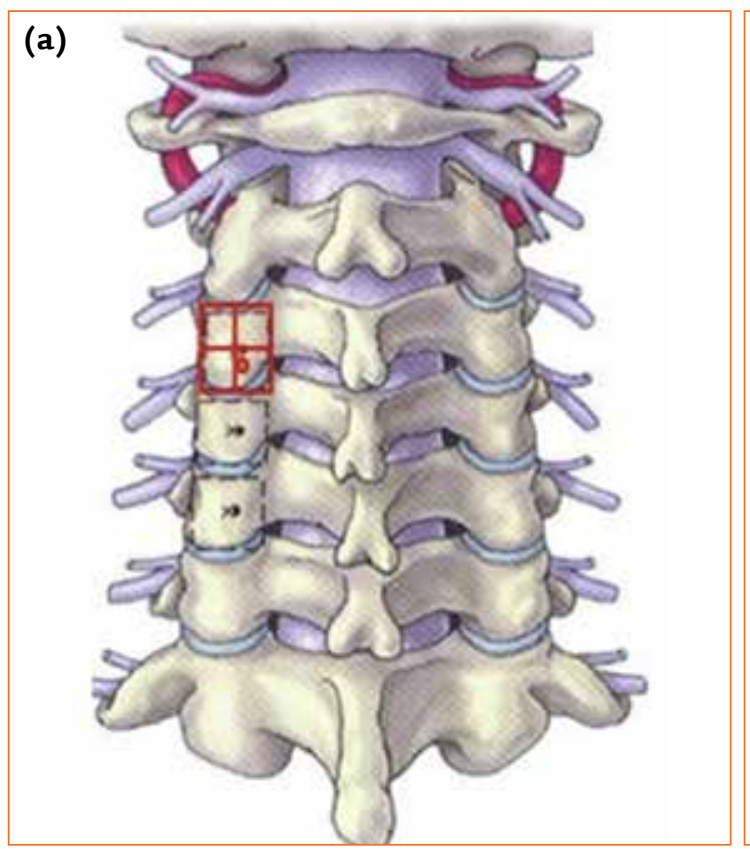

(c)

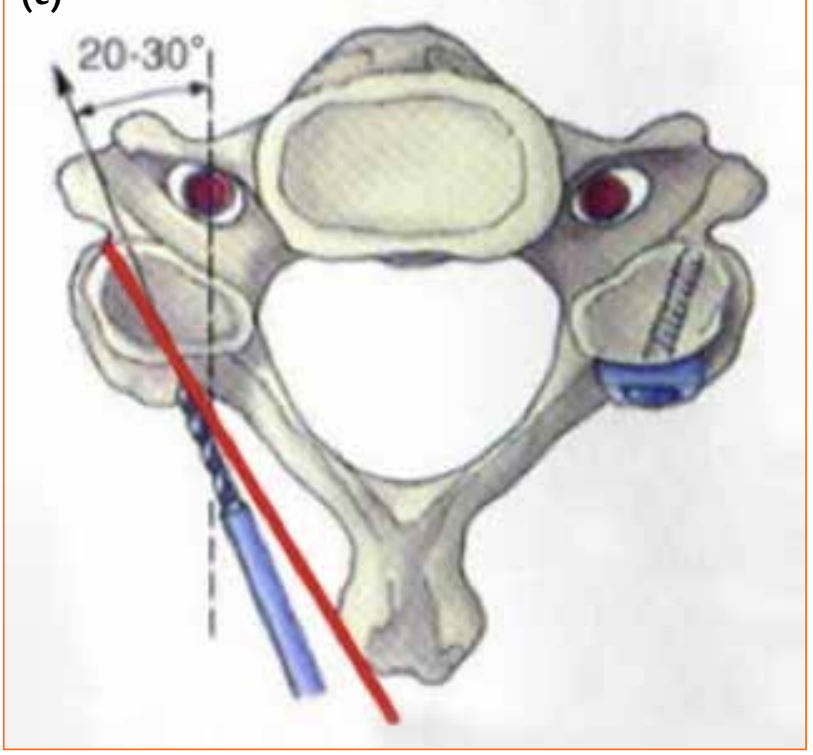

(b)

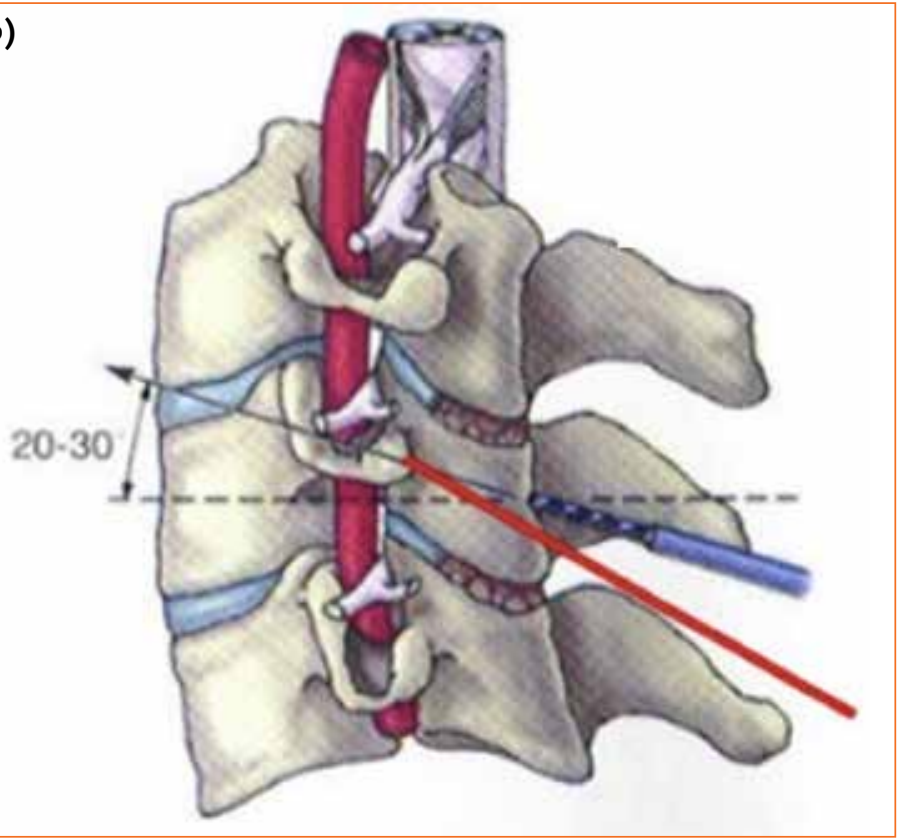

Şekil 4. a-c. Bizim tekniğimizle mass vidası giriş noktası ve vida trajeksiyonları.

olgularında ve ipsilateral vertebral arter anomalilerinde kontrendikedir. Doğru pedikül vidası yerleştirmek için, giriş açısıyla uygun eşleşmiş giriş noktasını iyi tespit etmek önemlidir. Bu amaçla dört yöntem tanımlanmıştır. Birincisi Albumi ve arkadaşları ${ }^{[17]}$ tarafından tanımlanan, ikincisi floroskopi ile pedikül aksının görüntülenmesi ile olan, ${ }^{[18]}$ üçüncüsü laminoforaminotomi ${ }^{[19]}$ ile ve dördüncüsü $\mathrm{BT}$ navigasyonla ${ }^{[23]}$ uygulanan yöntemlerdir.

Giriş noktası C3'ten C7'e doğru inerken, lateral mass'ın orta noktasının hafif lateraline ve komşu superior vertebranın inferior artiküler proçesinin inferioruna yaklaşır. Yani, C7 giriş noktası daha superior ve daha lateral iken C3 de C7'ye göre hafif mediyal ve hafif inferiordadır. Drill $45^{\circ}$ mediyale ve end-plate'e paralel olacak şekilde ilerletilir ya da kontrolateral laminaya paralel bir çizgi sagittal planda 3 mm'lik güvenli bir koridor sağlanır (Şekil 7). ${ }^{[24]}$ Diğer bir seçenek, pedikülün direkt görülmesi için yüksek hızlı burr ile lateral mass'ın açılmasıdır. Pedikül problanır ve tapp'lenir; sonra 3,5 $\mathrm{mm}$ vida yerleştirilir. Standart açılanma ve giriş noktası tehlikeli olabilir. Çünkü, C4 ve C6 arasında pedikül anatomisi ve yüzey anatomisi oldukça değişkendir. ${ }^{[9]}$ Pedikül çapı 4,5 mm'den küçükken laminoforaminotomi ile pedikül mediyalini direkt olarak palpe etmek veya navigasyon yardımıyla vidayı yerleştirmek güvenlidir. ${ }^{[25]}$ Sefalik malpozisyon, büyük olasılıkla sinir kökü 


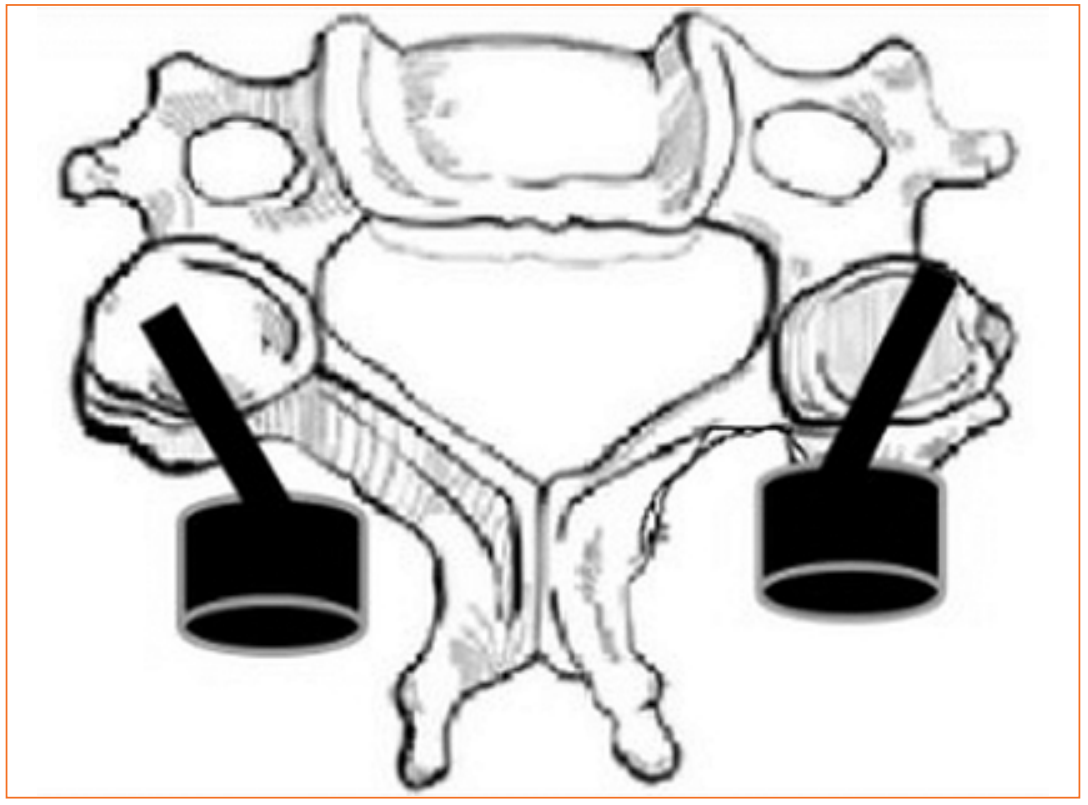

Şekil 5. Bizim tekniğimizde mass vidasının tam olarak oturması için laminanın tur ile tıraşlanması.
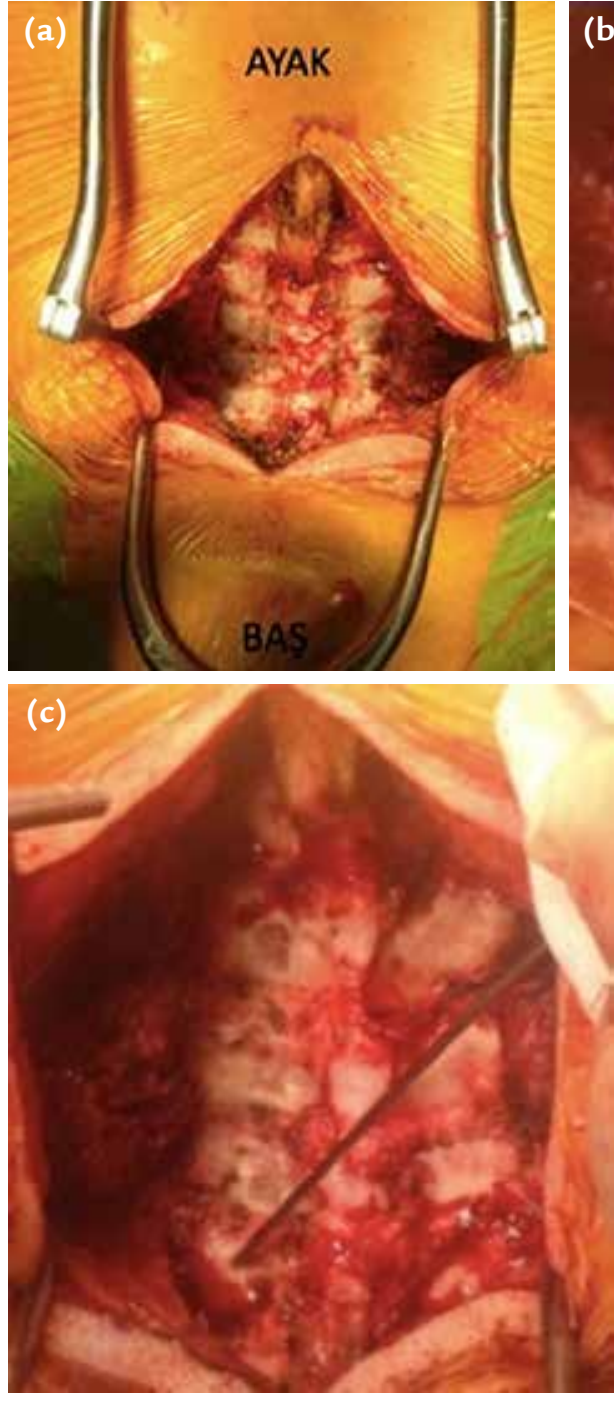
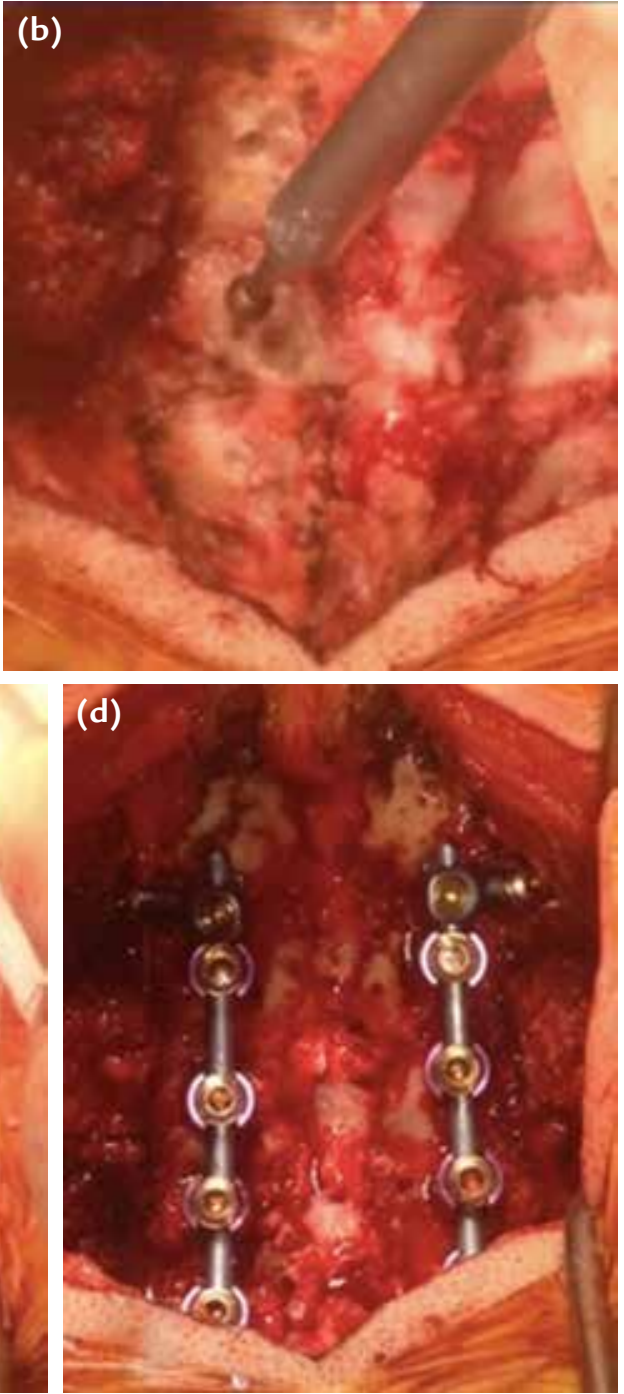

Şekil 6. a-d. Subperiostal disseksiyon ile lateral mass'ların açılması (a), tur motoru ile giriş yerlerinin işaretlenmesi ve laminanın tıraşlanması (b), Kirshner teli ile ilk giriş (c) ve mass vidalarının yerleştirilmesi (d). 


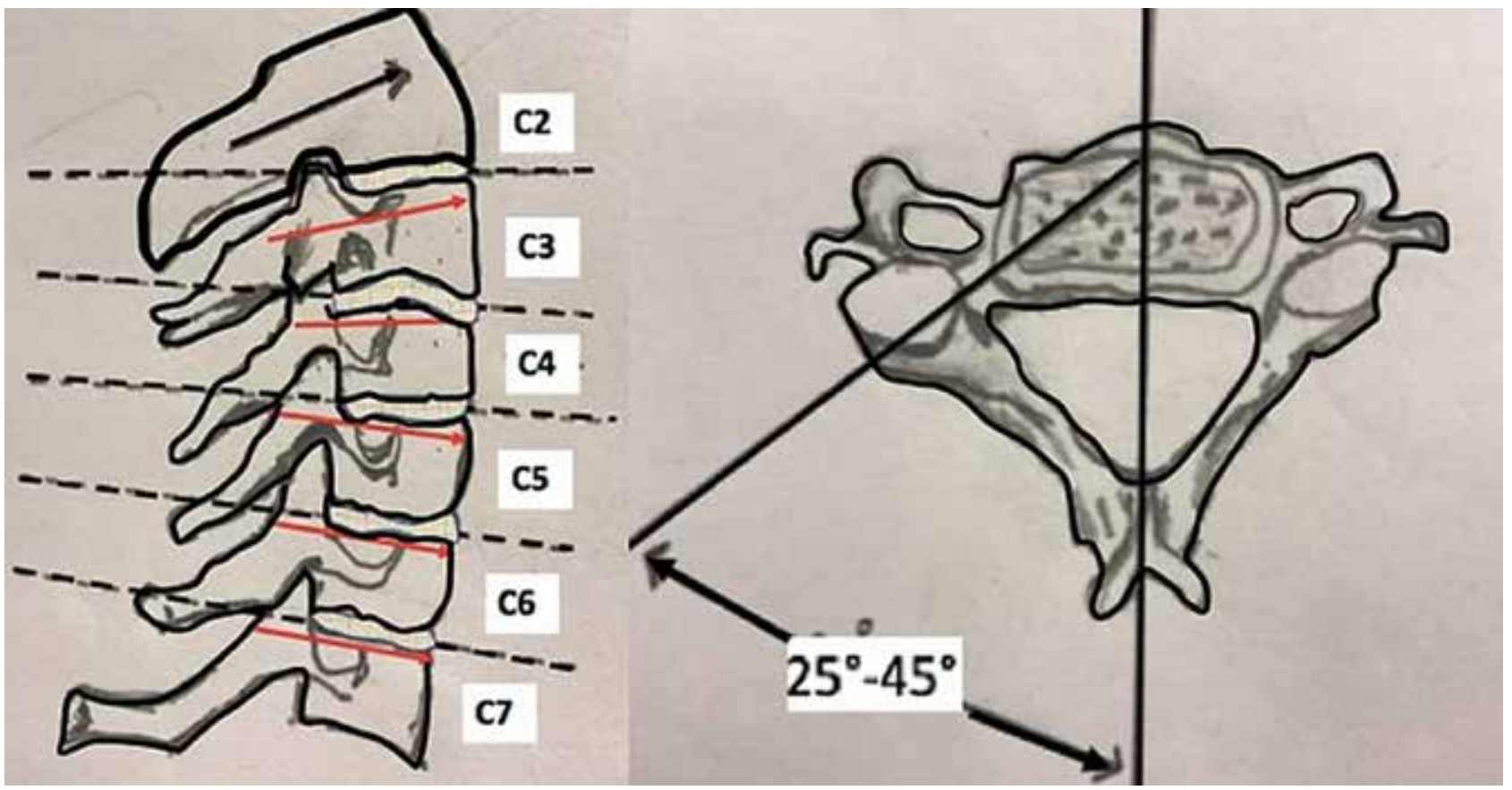

Şekil 7. Servikal pedikül vidalarının giriş noktalarının ve açılarının şematik görüntüsü.

hasarına neden olacaktır. Cerrahi sırasında elektromiyelografi, posterior servikal vida yerleştirilmesinde yardımcı olabilir.

\section{ANTERIOR SERVIKAL ENSTRÜMANTASYON}

Servikal omurga patolojilerinin tedavisinde hangi yaklaşımın tercih edileceği tartışmalı olmasına rağmen, son on yılda anterior yaklaşımlar daha çok yaygınlaşmıştır. Anterior yaklaşımlar, cerrahın ventral kompresif patolojilere aşırı kanama olmadan küçük insizyonla C2-C3'ten T1'e kadar direkt yaklaşımını sağlamaktadır. Dejeneratif servikal hastalıklarda anterior cerrahi girişimler, patolojinin genişliğine bağlı olarak, tek seviye diskektomi ve füzyonu, çoklu seviye diskektomi ve füzyonu, korpektomiyi, anterior plaklamayı veya bunların kombinasyonunu içerir (Şekil 8 ve 9).

\section{Anterior Servikal Diskektomi Füzyon (ACDF)}

Hem radikülopati hem de miyelopati tedavisinde sıklıkla uygulanan bir yöntemdir. İlgili seviyeye oblik insizyon sonrasında, platizma ve derinde servikal fasyanın süperfisiyel tabakası kesilir. Özefagus ve trakea mediyale ekarte edilir. Sternokleidomastoid kas ve karotis laterale retrakte edilir. Pretrakeal ve prevertebral fasya longitudinal şekilde açılır. Seviye radyolojik olarak doğrulandıktan sonra, büyütme altında diskektomi işlemi uygulanır. Osteofitler ve gerekli ise posterior longitudinal bağ eksize edilir. Unsinat proçesler çıkartılarak foraminotomi işlemi yapılabilir. Dekompresyon işlemi tamamlandıktan sonra endplate'ler füzyon ya da artroplasti işlemi için hazırlanır. Daha önceleri füzyon işlemi için diskektomi yapılan bölgeye otogreft yerleştirilirken; donör saha morbiditeleri ve greft kollapsı nedeniyle, günümüzde daha çok içerisine allogreft yerleştirilen interbody kafesler kullanılmaktadır. ${ }^{[26]}$

\section{Anterior Füzyon ve Destek İçin Kullanılan Materyaller}

\section{Kemik greftleri}

Kemik strut greftler, korpektomi sonrasında kullanılan erken dönem materyallerdir. iliak krest kemik, strüktürel otogreft için en yaygın kullanılan kaynaktır. Fibular strut allogreft ve otogreft olarak radius, kosta ve diğer kemikler daha nadir kullanılan kaynaklardır. Greftin şekli ve boyutu, kollapsın önlenmesi ve füzyon başarısı için oldukça önemlidir. ${ }^{[27]}$ Trikortikal iliak otogreft çok fazla kansellöz kemik içerir ve erken füzyon başarısını arttırır. Ancak, dönör saha morbiditelerine neden olur. Multi-seviye korpektomilerde fibular strut greft çok kullanışıdır. Fibular greft, santralinde kemik iliği boşluğuna sahiptir ki bu kemik ile dolarak füzyon başarısını arttırmaktadır. ${ }^{[28]}$ 

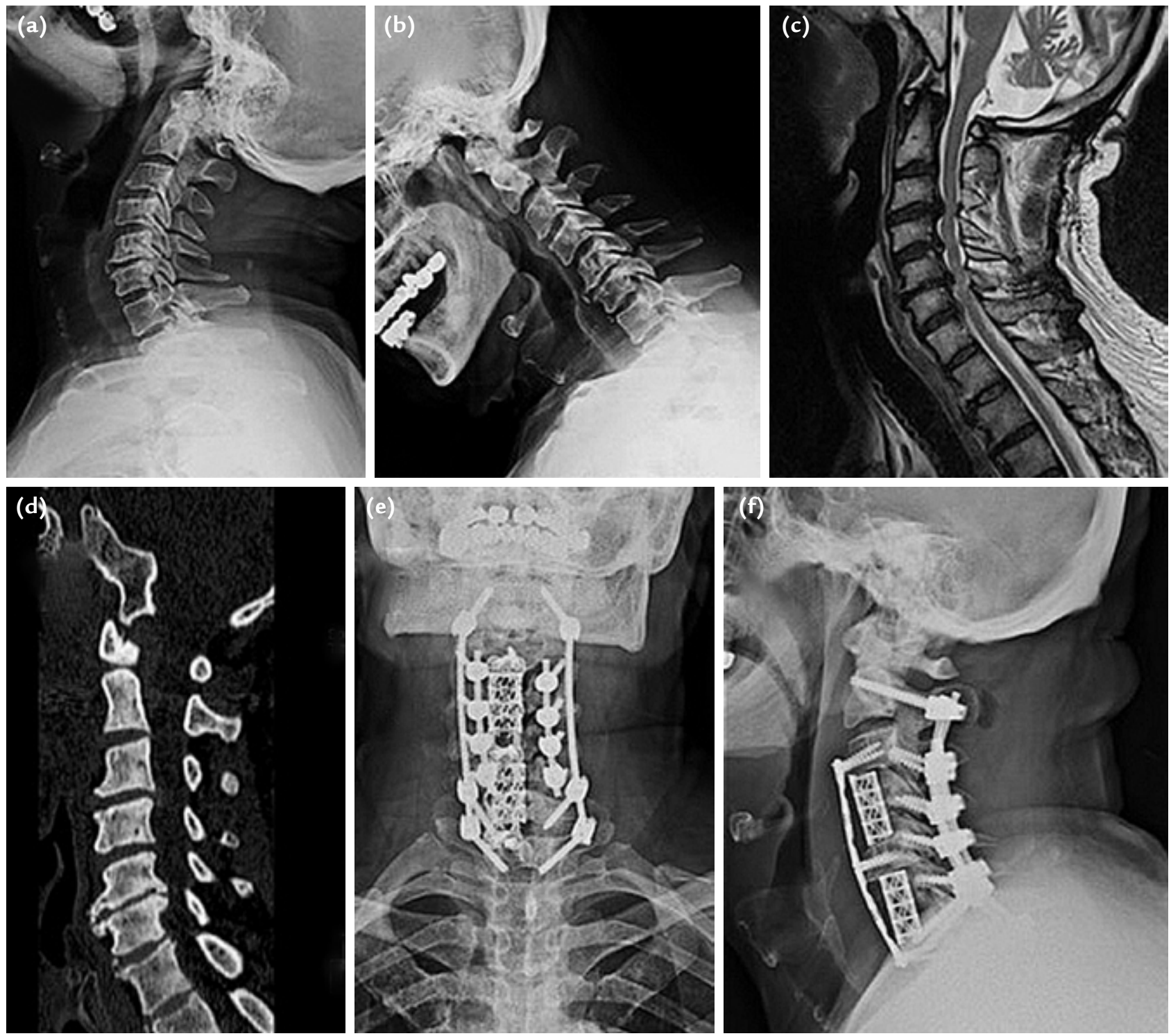

Şekil 8. a-f. Yürüme bozukluğu ve kollarında güçsüzlük şikayetleri olan 78 yaşında erkek hastanın ameliyat öncesi servikal dinamik grafileri (a, b), sagittal MR kesiti (c), sagittal BT kesiti (d), anterior iki seviye (C4, C6) korpektomi (mesh kafes ve plak) ve posterior enstrümantasyon (C2 ve C7, T1 pedikül vidası, C3-C6 mass vidası ve çift rod tekniği ile sistemin bağlanması) sonrasında ön-arka (e) ve yan grafileri (f).

\section{Polimetilmetakrilat rekonstrüksiyon (PMMA)}

Özellikle kanser hastalarında füzyon olmaksızın hemen bir stabilizasyon sağlaması ve ucuz olması nedeniyle oldukça fazla kullanılmaktadır. Tümör invazyonundan etkilenmez ve hemen sonrasında radyoterapi uygulanması için oldukça güvenilirdir. ${ }^{[29]}$

\section{Titanyum mesh kafes (cage) - Harms kafesi}

Titanyum mesh kafesler, 1986 yılında tanımlanmasından bu yana spinal rekonstrüksiyonlarda sıklıkla kullanılmaktadır. Bu kafeslerle; içerisine otogreft yerleştirilerek strüktürel destek sağlanmaktadır (Şekil 9). Avantajı, istenilen boyutta şekillendirilebilir olmasıdır. Dezavantajları; pahalı olması, end-plate kapsama güçlükleri ve füzyonu değerlendirmenin güç olmasıdır. Majör komplikasyonu, özellikle osteoporotik hastalarda materyal yetmezliği ve end-plate kollapsıdır. Belirgin bir kollaps (>3 mm) olmadığı sürece klinik sonuçları etkilemeyebilir. ${ }^{[28]}$ 

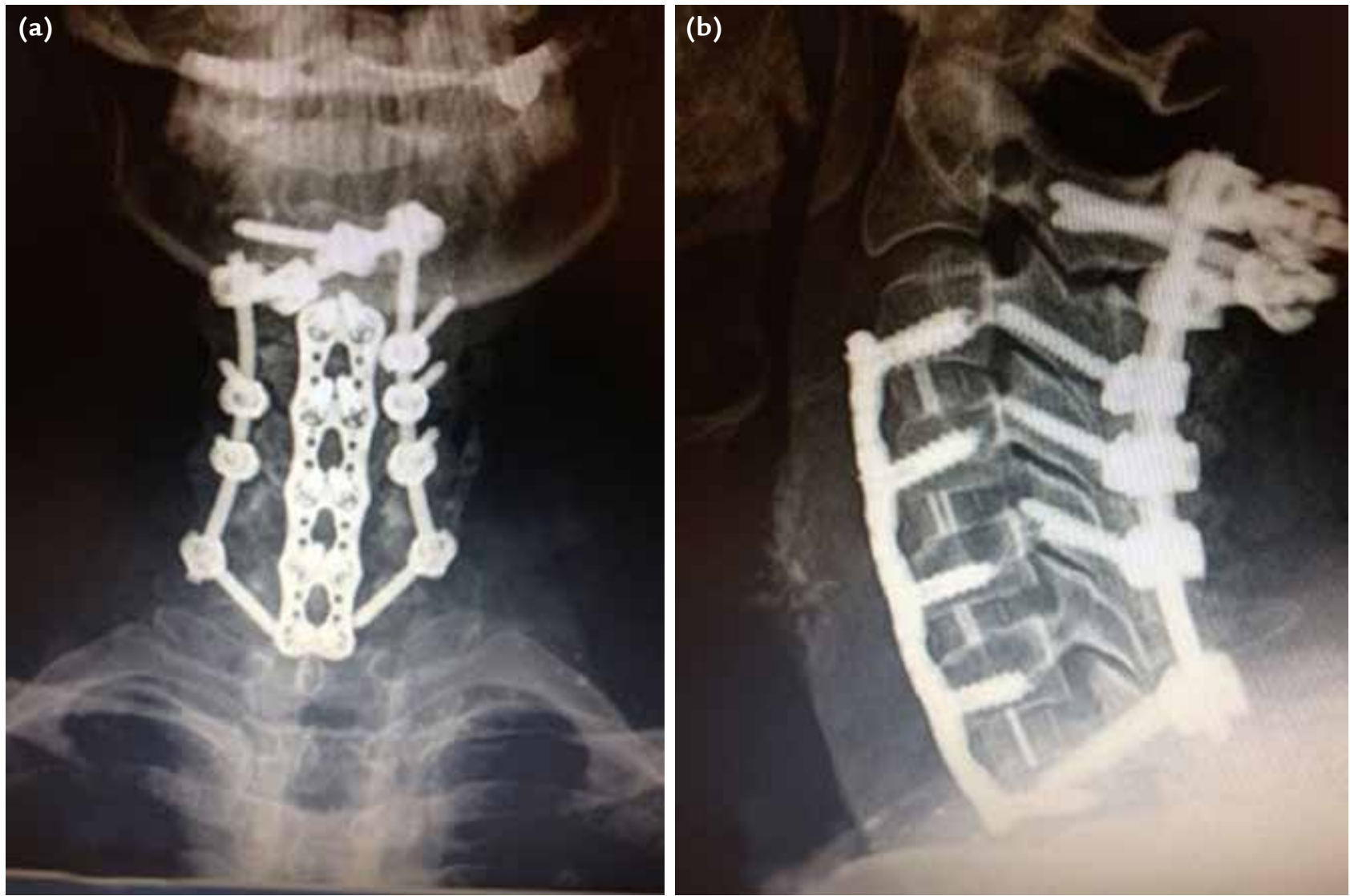

Şekil 9. a, b. Multi-seviye servikal dejeneratif disk hastalı̆̆ı tanısıyla anterior dört seviye diskektomi, kafes ve plak, posteriordan yüksekten dönen vertebral arter nedeniyle C2'ye intralaminar vida ve alt servikal mass vidaları (C6 atlanarak C7'ye pedikül vidası) yerleştirilen hastanın ameliyat sonrası ön-arka (a) ve yan (b) grafileri.

\section{Modüler kafes}

Polietereterketon (PEEK) kafesler, anterior servikal interbody füzyon için oldukça popüler olmaya başlamış bir interbody greft materyalidir. Korpektomi için PEEK, karbon fiberle güçlendirilmiş PEEK (CFRP) ve titanyumu içeren diğer materyaller kullanılarak çeşitli yüksekliklerde kafesler tasarlanmıştır. Plastik ve karbon fiber kafesler, kemiğin elastik modülüsüne yakın olduğu için denenmektedir. Teorik olarak, bunların tensil ve kompresif kuvvetleri kemik üzerinde stress shielding oluşturmadan kafes içerisinden aktardığı düşünülmektedir. CFRP'nin gücü PEEK'ten iki kat fazladır. Her ikisi de kemik grefti ile doldurulabilmektedir. ${ }^{[28]}$

\section{Genişleyebilen kafesler}

Genişleyebilen kafesler, korpektomi sonrasında kullanılan son nesil kafeslerdir. Mesh kafeslere göre daha rahat yükseklik sağlanabilmektedir. Dezavantajı ise, diğer basit kafeslere oranla daha az kemik grefti yerleştirilmesidir; fakat, çalışmalarda yüksek füzyon oranları bildirilmiştir. ${ }^{[30]} \mathrm{Bu}$ kafesler mükemmel bir yapısal destek sağlamakta, aynı zamanda end-plate'te çok fazla kompresif yük oluşturmakta ve servikal kifozu ve sagittal restorasyonu çok iyi şekilde sağlamaktadır. Genişleyebilen kafesler, allogreftle kombinasyona rağmen vertebral osteomiyelitte rekürrens oranının çok düşük olması nedeniyle oldukça sık kullanılmaktadır. ${ }^{[31]}$

\section{Anterior Servikal Plak Uygulaması}

Greft kullanılarak yapılan servikal interbody füzyonun iyileşme döneminde, her bir mesafede yaklaşık 1-2 mm rezorpsiyon oluşur. Plaklar teorik olarak, greft üzerine binen yükü önler ve grefti basınçtan korur. Servikal plaklar, geri çekme gücü engellenemeyen, tutucu (statik) ve kısmen tutucu plaklar olarak iki gruba ayrılmaktadır. Kısmen tutucu plaklar ise rotasyonel (dönme hareketi olanlar) ve translasyonel (kayma hareketi olanlar) olmak üzere 
iki gruptur. Geri çekme gücü engellenemeyen plaklar artık kullanılmamaktadır. Bunlarda kilit sistemi yoktur ve vida bikortikal yerleştirilmelidir. Tutucu veya statik plaklar, kilit sistemi olan, vidanın geri çekme gücü olmadan unikortikal tespit sağlayan plaklardır.

Kısmen tutucu ve dinamik plaklar, greftin mekanik ve biyolojik olarak küçülme potansiyeline uyumlu olacak şekilde aksiyel planda hareketine izin veren plaklardır. Anterior plaklar, travma veya tümör gibi destrüktif lezyonların neden olduğu instabilitelerde ve dejeneratif hastalıklarda dekompresyon sonrasında sıklıkla kullanılmaktadır. Özellikle iki veya üç seviye füzyon olgularında, füzyon başarısını arttırdığı düşünülmektedir. Tek seviyeli füzyon olgularında kullanımı tartışmalıdır. Dinamik plakların statik plaklara göre daha etkili olduğunun kanıtları henüz ortaya konulmamıştır. Üç veya dört seviye uzun füzyon yapılan olgularda statik plaklar kullanıldığında, plağın kaudal kısmındaki vidaların gevşeyip greftin kollapsına bağlı başarısızlığa neden olma oranı yüksektir. Bu nedenle, uzun seviye füzyonlarda yazarlar translasyonel plakların kullanılmasını önermektedir. Osteoporozlu ve renal osteodistrofili hastalarda, ciddi kifotik deformitelerde, total bağ hasarında, şiddetli omurga kırığı veya posterior elemanların yokluğu ile birlikte olan instabilitelerde, dikkatli kullanılmalıdır. Plak tam olarak ortaya yerleştirilmeli ve komşu segmente zarar vermemesi için olabildiğince kısa olmalıdır. Cerrahi öncesi vida boyları belirlenebilir. Genellikle, 14-16 mm vidalar stoplu drill'erle yer açıldıktan sonra yerleştirilir. Proksimalde kraniyale, distalde kaudale açılı vidalar yerleştirilmelidir (Şekil 8 ve 9). ${ }^{[32]}$

\section{Servikal Artroplasti}

Anterior servikal diskektomi ve füzyon (ASDF) uzun zamandır semptomatik servikal disk hastalığının primer tedavisinde altın standart olmuştur. Bunun yanında, ASDF çok iyi bir klinik iyileşme sağlarken, hareketli segment kaybı, potansiyel komşu segment dejenerasyonu günümüzde tartışılan konular olmuştur. ASDF'nin bu potansiyel ve istenmeyen dezavantajlarını ortadan kaldırmak amacıyla, son birkaç on yıldır servikal disk hastalığının tedavisinde hareketi koruyan servikal protezler kullanılmaya başlamıştır. Anterior servikal artroplasti (ASA) için endikasyonlar ASDF ile benzerdir; cerrahi endikasyonlar; C3 ve C7 arasında semptomatik disk hastalığı (radikülopati ve/veya miyelopati), servikal disk hernisi, osteofit formasyonu, disk yükseklik kaybı, fonksiyonel defisit, en az altı haftalık cerrahi dışı tedaviyle iyileşmeyen progresif nörolojik defisiti içerir.
ASA için kontrendikasyonlar olarak; komponent, metal veya plastik alerjisi, aktif lokal veya sistemik enfeksiyon, T-skorun 2,5'ten küçük olduğu osteoporoz, belirgin kifotik deformite, orta ve ilerlemiş spondilozis, köprüleşmiş osteofit, disk yüksekliğinin \%50'den fazla kaybı, implantasyon düşünülen seviyede hareket olmaması, fleksiyon-ekstansiyon grafilerinde 3 mm'den fazla translasyon veya komşu seviye ile karşılaştırıldığında $11^{\circ}$ 'den fazla angülasyona neden olan belirgin instabilite bulguları, tedavi gerektiren çoklu seviye servikal disk hastalığı, faset eklem artrozu sayılabilir. ${ }^{[33]}$

Servikal artroplasti cerrahi tekniği, ASDF işlemine benzer. Bununla birlikte, dikkat edilmesi gereken noktalar; hastanın pozisyonu floroskopi ile çok iyi hazırlanması (hastanın normal lordozu sağlanmalı, hiperekstansiyondan kaçınılmalıdır) ve retraktör pinlerinin üsteki vertebranın üst $1 / 3$ bölümüne, alttaki vertebranın alt $1 / 3$ bölümüne yerleştirilmesidir. End-plate hasarlanmamalıdır. Titiz bir şekilde tam bir dekompresyon sağlanmalıdır. Gerekirse posterior longitudinal bağ kesilmelidir. Asemptomatik stenozun olduğu bölgeler mutlaka dekomprese edilmelidir. Protez boyutu cerrahi öncesi BT ölçümleri ile belirlenebilir. Vertebral end-plate'i kapsamalı, komşu disk mesafesi ile aynı yükseklik hedeflenmelidir. Posterior sınırı vertebra posterioruna flash olacak şekilde ayarlanmalıdır. Protez tam merkezi olacak şekilde yerleştirilmelidir (Şekil 10). Şu an halihazırda ticari olarak kullanılan birçok servikal disk protez tasarımı mevcuttur. Bunların cerrahi teknikleri birbirlerine benzemektedir. Goffin Brayn, disk (Medtronic Sofamar Danek) ile tedavi ettiği 60 servikal disk hastasında erken dönem sonuçları mükemmel olarak bildirmiştir. Wigfield, iki yıl takipli servikal disk protezi ile tedavi ettiği hastalarında Prestige I tasarımının (Medtronic Sofomar Danek, Mempis, TN) sonuçlarının iyi olduğunu bildirmiştir. ${ }^{[34]}$

Sonuç olarak; servikal dejeneratif hastalıklarda hastaya, cerrahın tecrübesine ve patolojinin yerleşim yerine göre değişen anterior ve posterior enstrümantasyon sistemleri mevcuttur. Servikal bölge, enstrümantasyon açısından oldukça zorluklar içeren anatomik yapılara sahiptir. Bu yüzden, seçeceğimiz enstrümantasyonun anatomik yapılara yakınlığı açısından, anjiyografi, MR ve BT gibi görüntüleme yöntemi ile cerrahi öncesi hazırlık oldukça önemlidir. 

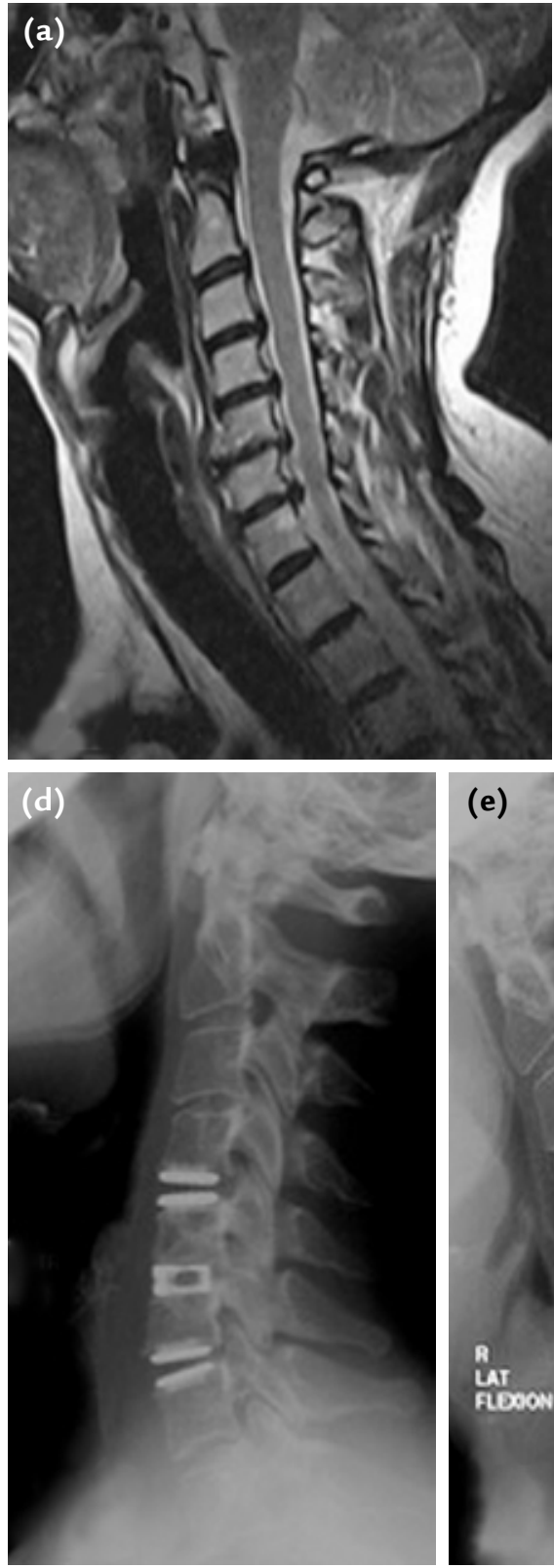

(e)
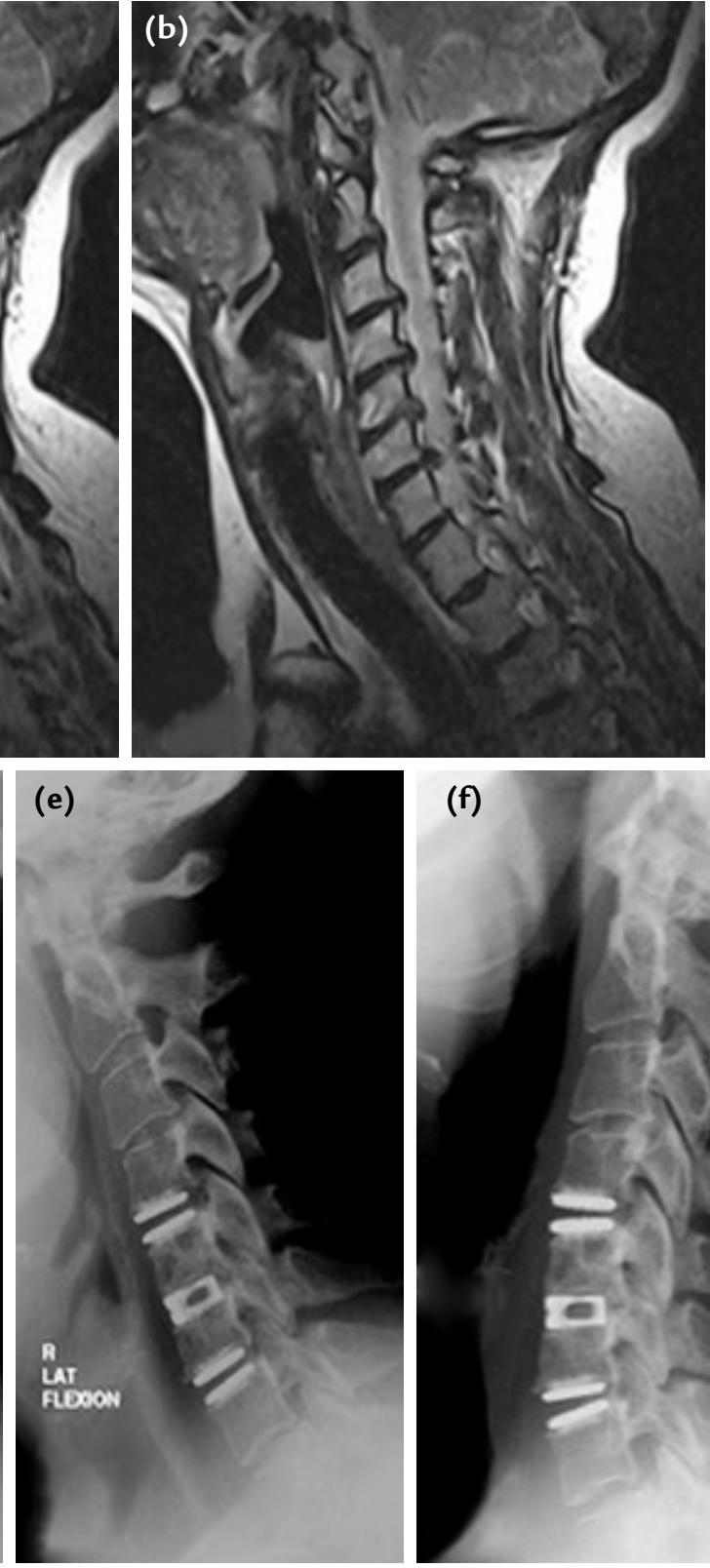

(f)

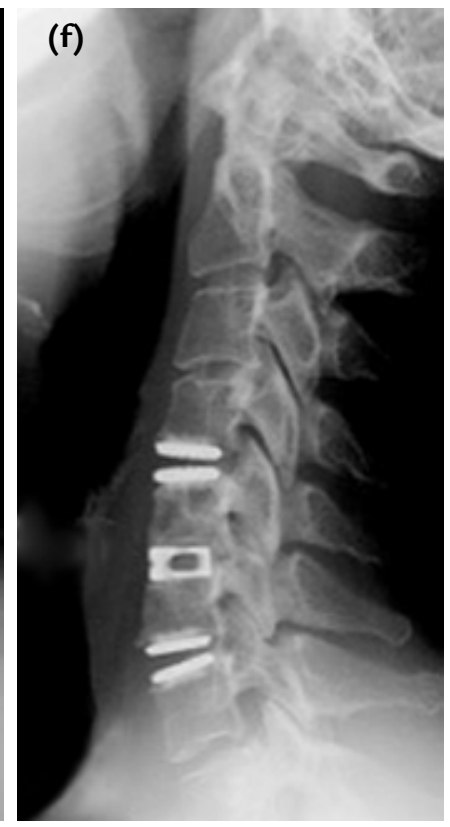

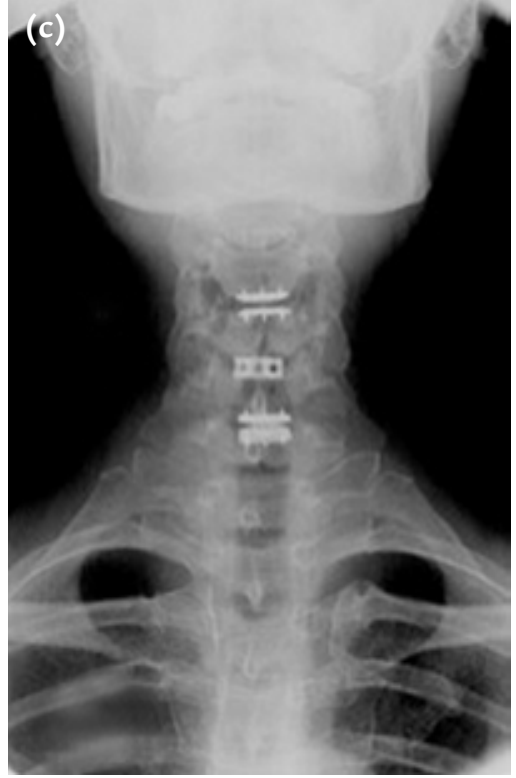

Şekil 10. a-f. Elli bir yaşında bayan hasta üç seviye servikal dejeneratif disk hastalığı mevcut. Hastanın ameliyat öncesi MR sagittal kesitleri (a, b), C4-C5 ve C6-7'ye servikal disk replasmanı, C5-C6'ya füzyon yapıldıktan iki yıl sonraki ön-arka (c), nötral yan (d), fleksiyonda yan (e) ve ekstansiyonda yan (f) grafileri.

\section{KAYNAKLAR}

1. Cloward RB. Treatment of acute fractures and fracturedislocations of the cervical spine by vertebral-body fusion. A report of eleven cases. J Neurosurg 1961;18:201-9. Crossref

2. Robinson RA, Southwick WO. Indications and technics for early stabilization of the neck in some fracture dislocations of the cervical spine. South Med J 1960;53:565-79.

3. Böhler J. Immediate and early treatment of traumatic paraplegias. Z Orthop Ihre Grenzgeb 1967;103(4):512-29.
4. Hacker RJ, Cauthen JC, Gilbert TJ, Griffith SL. A prospective randomized multicenter clinical evaluation of an anterior cervical fusion cage. Spine (Phila $\mathrm{Pa} 1976$ ) 2000;25(20):2646-54.

5. Hadra BE. The classic: Wiring of the vertebrae as a means of immobilization in fracture and Potts' disease. Berthold E. Hadra. Med Times and Register, Vol22, May 23, 1891. Clin Orthop Relat Res 1975;(112):4-8.

6. Roy-Camille R, Saillant G, Laville C, Benazet JP. Treatment of lower cervical spinal injuries -C3 to C7. Spine (Phila Pa 1976) 1992;17(10 Suppl):S442-6. 
7. Cooper PR, Cohen A, Rosiello A, Koslow M. Posterior stabilization of cervical spine fractures and subluxations using plates and screws. Neurosurgery 1988;23(3):300-6.

8. Harms J, Melcher RP. Posterior C1-C2 fusion with polyaxial screw and rod fixation. Spine (Phila Pa 1976) 2001;26(22):2467-71.

9. Aryan HE, Newman CB, Nottmeier EW, Acosta FL Jr, Wang $\mathrm{V}$, Ames CP. Stabilization of the atlantoaxial complex via C-1 lateral mass and $\mathrm{C}-2$ pedicle screw fixation in a multicenter clinical experience in 102 patients: modification of the Harms and Goel techniques. J Neurosurg Spine 2008;8(3):222-9. Crossref

10. Yeom JS, Buchowski JM, Park KW, Chang BS, Lee CK, Riew KD. Undetected vertebral artery groove and foramen violations during C1 lateral mass and C2 pedicle screw placement. Spine (Phila Pa 1976) 2008;1;33(25):942-9. Crossref

11. Wright NM. Posterior $C 2$ fixation using bilateral, crossing $C 2$ laminar screws: case series and technical note. J Spinal Disord Tech 2004;17(2):158-62.

12. Ebraheim NA, Fow J, Xu R, Yeasting RA. The location of the pedicle and pars interarticularis in the axis. Spine (Phila $\mathrm{Pa}$ 1976) $2001 ; 15 ; 26(4): E 34-7$.

13. Kalani MYS, Erfan IF, Dickman CA. C1-C2 trauma injuries and stabilization techniques. In: Kim D, Vaccaro AR, Dickman CA, Cho D, Lee S, Kim I, editors. Surgical Anatomy and Techniques to the Spine, 2nd ed. Philadelphia: Elsevier/ Saunders; 2013. p.110-18.

14. Panjabi M, Dvorak J, Duranceau J, Yamamoto I, Gerber M, Rauschning W, Bueff HU. Three-dimensional movements of the upper cervical spine. Spine (Phila Pa 1976) 1988;13(7):726-30.

15. Bransford RJ, Stevens DW, Uyeji S, Bellabarba C, Chapman JR. Halo vest treatment of cervical spine injuries: a success and survivorship analysis. Spine (Phila $\mathrm{Pa}$ 1976) 2009;1;34(15):1561-6. Crossref

16. Grob D, Crisco JJ 3rd, Panjabi MM, Wang P, Dvorak J. Biomechanical evaluation of four different posterior atlantoaxial fixation techniques. Spine (Phila Pa 1976) 1992;17(5):480-90.

17. Abumi $\mathrm{K}$, Itoh $\mathrm{H}$, Taneichi $\mathrm{H}$, Kaneda $\mathrm{K}$. Transpedicular screw fixation for traumatic lesions of the middle and lower cervical spine: description of the techniques and preliminary report. J Spinal Disord 1994;7(1):19-28.

18. Yukawa $\mathrm{Y}$, Kato $F$, Yoshihara $\mathrm{H}$, Yanase M, Ito K. Cervical pedicle screw fixation in 100 cases of unstable cervical injuries: pedicle axis views obtained using fluoroscopy. J Neurosurg Spine 2006;5(6):488-93. Crossref

19. Ludwig SC, Kramer DL, Vaccaro AR, Albert TJ. Transpedicle screw fixation of the cervical spine. Clin Orthop Relat Res 1999;(359):77-88.

20. Jeanneret B, Magerl F, Ward EH, Ward JC. Posterior stabilization of the cervical spine with hook plates. Spine (Phila Pa 1976) 1991;16(3 Suppl):S56-63
21. An HS, Gordin R, Renner K. Anatomic considerations for plate-screw fixation of the cervical spine. Spine (Phila Pa 1976) 1991;16(10 Suppl):S548-51.

22. Anderson PA, Henley MB, Grady MS, Montesano PX, Winn HR. Posterior cervical arthrodesis with $A O$ reconstruction plates and bone graft. Spine (Phila Pa 1976) 1991;16(3 Suppl):S72-9.

23. Kotani $Y$, Abumi K, Ito M, Minami A. Improved accuracy of computer-assisted cervical pedicle screw insertion. J Neurosurg 2003;99(3 Suppl):257-63.

24. Hacker AG, Molloy S, Bernard J. The contralateral lamina: a reliable guide in subaxial, cervical pedicle screw placement. Eur Spine J 2008;17(11):1457-61. Crossref

25. Ludwig SC, Kramer DL, Balderston RA, Vaccaro AR, Foley KF, Albert TJ. Placement of pedicle screws in the human cadaveric cervical spine: comparative accuracy of three techniques. Spine (Phila Pa 1976) 2000;25(13):1655-67.

26. Bolesta MJ, Gill K. Acute neck pain and cervical disk herniation. In: Spivak JM, Connolly PJ, editors. Orthopaedic Knowledge Update. Spine 3. Rosemont, California: AAOS; 2006. p.227-34.

27. Ikenaga M, Shikata J, Tanaka C. Anterior corpectomy and fusion with fibular strut grafts for multilevel cervical myelopathy. J Neurosurg Spine 2005;3(2):79-85. Crossref

28. Choudhri Omar, Ryu SI. Cervical corpectomy, fusion, and vertebral restoration techniques. In: Kim D, Vaccaro A, Dickman C, Cho D, Lee S, Kim I. Surgical Anatomy and Techniques to the Spine, 2nd ed. Philadelphia: Elsevier/ Saunders; 2013. p.162-81.

29. Liu JK, Apfelbaum RI, Schmidt MH. Surgical management of cervical spinal metastasis: anterior reconstruction and stabilization techniques. Neurosurg Clin $\mathrm{N} A m$ 2004;15(4):413-24. Crossref

30. Woiciechowsky C. Distractable vertebral cages for reconstruction after cervical corpectomy. Spine (Phila Pa 1976) 2005;30(15):1736-41.

31. Lu DC, Wang V, Chou D. The use of allograft or autograft and expandable titanium cages for the treatment of vertebral osteomyelitis. Neurosurgery 2009;64(1):122-9. Crossref

32. Jensen WK, Anderson PA. Anterior cervical plating: Static and dynamic. In: Vaccaro AR, Albert TJ, editors. Spine Surgery. Tricks of the Trade, 2nd ed. New York: Thieme Medical Publishers; 2009. p.79-82.

33. Kesman TJ, Darden BV. Anteriror cervical arthroplasty. In: Zdeblick TA, Albert TJ, editors. Master Techniques in Orthopaedic Surgery: The Spine, 3rd ed. Philadelphia: Lippincott Williams \& Wilkins; 2013. p.37-49.

34. Sasso RC, Garrido BJ. Cervical Disk Replacement. In: Vaccaro AR, Albert TJ, editors. Spine Surgery. Tricks of the Trade, 2nd ed. New York: Thieme Medical Publishers; 2009. p.294-7. 